\title{
Effect of Repeated Microwave Disinfection on Surface Hardness and Dimensional Accuracy of Two Dental Stone Materials
}

Mahmood Robati Anaraki ${ }^{1,2}$, Elnaz Moslehifard ${ }^{1,2}$,Mahmoud Bahari ${ }^{1,3}$, Shiva Mahboubi ${ }^{4 *}$

1. Dental and Periodental Research Center, Tabriz University of Medical Science, Tabriz, Iran

2. Assistant Professor, Department of Prosthodontics, Dental School, Tabriz University of Medical Science, Tabriz, Iran

3. Assistant Professor, Department of Operative Dentistry, Dental School, Tabriz University of Medical Science, Tabriz, Iran

4. Post-graduate Student, Department of Prosthodontics, Dental School, Tabriz University of Medical Science, Tabriz, Iran

\begin{abstract}
There is controversial evidence in relation to the effect of microwave on mechanical properties of stone casts. The present study was designed to evaluate the effect of repeated microwave disinfection on surface hardness and dimensional accuracy of dental stone. In this in vitro study, 48 cylindrical stone samples were prepared using two products of type IV stone to assess surface hardness and 48 impressions were taken from a model and poured by these stones to assess the dimensional accuracy. The evaluation of the samples was carried out consequently by a micro-hardness tester and a digital caliper after the stone samples were exposed to 7 consecutive rounds of 900 watts (W) microwave irradiation for five minutes each time after cooling. Data were analyzed by t-test and ANOVA. According to the obtained results, multiple disinfections of the stone casts by microwave do not negatively affect their surface hardness and dimensional accuracy.
\end{abstract}

Key words: Dental stone; Dimensional accuracy; Hardness; Microwave

\section{Introduction}

Dental stone casts should be disinfected several times because of multiple transfers between the clinic and the laboratory $(1,2)$. Applying the chemical disinfection as a traditional technique is now questionable because of new generation of pathogenic microorganisms, questionable microbicidal efficiency, and detrimental effects on some of the commonly used impression materials such as irreversible hydrocolloid and stone casts (35). As a result, physical disinfection techniques such as microwave irradiation have been introduced for heat-resistant objects like stone casts.

\section{Corresponding author:}

Shiva Mahboubi

Post-graduate Student, Department of Prosthodontics, Dental School, Tabriz University of Medical Science, Tabriz, Iran E-mail: mahbobi-sh62@hotmail.com Phone number: +989185756810 Cell phone: +989187008375

Receive date: 2014-08-15| Accept date: 2014-08-28| Publish date: 2014-09-12

DOI: 10.7575/aiac.abcmed.15.03.01.06 
The success in disinfection by microwave irradiation of stone cast at energy level of $900 \mathrm{~W}$ (6) encouraged further studies to evaluate the possible changes in basic properties of stone casts within the irradiation at this level and microbicidal effectiveness of microwave versus more microorganisms with more persistency. The reported results showed efficient disinfection of the cast, not affecting most physical and mechanical properties like dimensional accuracy, surface roughness, compressive and tensile strength and detail reproduction at $800-900 \mathrm{~W}$ after one cycle of irradiation (7-10).

It is not known whether multiple application of these procedures that are necessary to prevent the cross-contamination during different procedures of making the prosthesis, is safe for the stone cast, especially for dimensional accuracy and surface hardness, as two basic properties. Therefore, in order to evaluate $900 \mathrm{~W}$ energy level, as an effective disinfection technique in microwave irradiation, the aim of the present study was to evaluate whether repeated irradiation at 900W energy level has any detrimental effects on the dimensional accuracy and surface hardness of stone casts according to ANSI/ADA standard No. 25 (11).

\section{Materials and Method}

\section{Surface Hardness}

A total of 48 cylindrical PVC tubes, measuring 2 centimeter $(\mathrm{cm})$ in diameter and 1 $\mathrm{cm}$ in height, were used to produce 48 cylindrical stone samples. The tubes were fixed on glass slabs using sticky wax (Model Cement 500G, Kemdent, UK) in order to produce a smooth surface on the base of the stone samples (Figure 1).

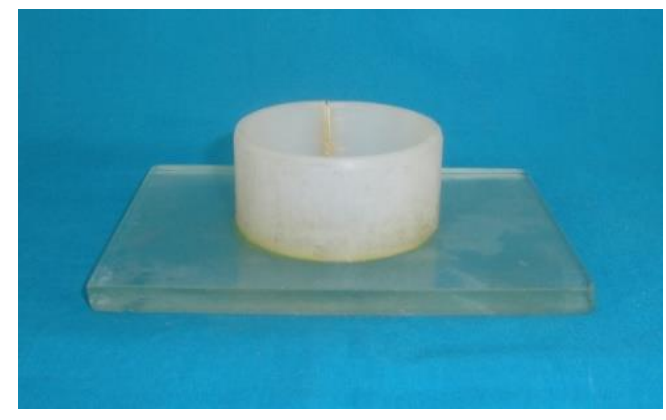

Figure 1: PVC cylinders were fixed on glass slabs by sticky waxed on glass slabs by sticky wax

The samples were poured with two products of type IV stone (Dentona, ZERT, Germany/Ernst Hinrichs, Goslar, Germany). According to manufacturer's instructions, stone powder and water were mixed first by hands and then placed in a vacuum mixer (Multirac 4, Degussa AG, Frankfurt, Germany) for 25 seconds under vacuum condition of 0.8 to 1 $\mathrm{mm} \mathrm{Hg}$ to eliminate porosity. Afterwards, the mix was poured into the molds by gentle vibration until slightly overfilled and then another glass slab was placed on each mold. The samples were retrieved from the molds one hour after pouring and were kept under laboratory conditions $\left(23^{\circ} \mathrm{C} \pm 2\right.$ and relative humidity of $23 \% \pm 3$ ). After 24 hours the samples of each product were randomly assigned to two case and control groups ( $\mathrm{n}=$ 12) (Figure 2).

The samples of the case group were placed in a microwave oven for seven consecutive cycles of each 5 minutes and irradiated by 900W microwave. Between the cycles the molds were cooled for 40 minutes. A beaker containing $200 \mathrm{~mL}$ of water was placed in the oven to protect the device wave-producing apparatus (magnetron). During each run, only 6 samples were placed on a circle around the center of the rotating tray of the oven so that all the samples would evenly receive the microwave rays. 


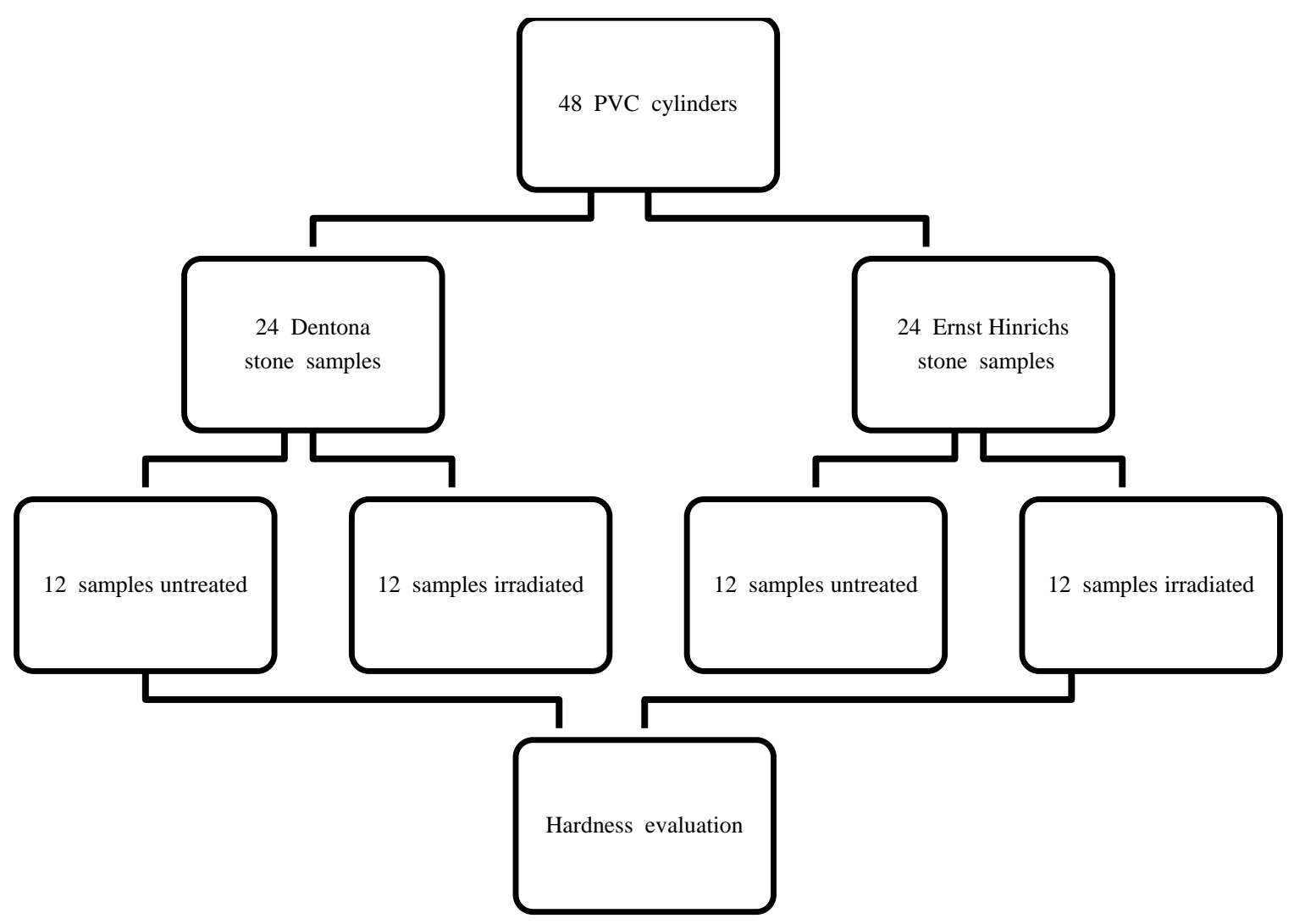

Figure 2: The flowchart of surface hardness experiment

The surface hardness measurement of the case and control samples was carried out by a microhardness tester (UHL VMTH Auto Microhardness Tester, Germany), using Vickers scale by an expert person blinded to the study procedure. Based on the Vickers scale, a diamond pyramid-shaped indenter applied a $2000 \mathrm{GF}$ (gram-force) for 15 seconds at a rate of $30 \mu \mathrm{m} / \mathrm{s}$ on the samples. Then, the dimensions of the depressions produced were measured under the photomicroscope coupled with tester machine at $\times 10$. This procedure was repeated on three different locations on the base of the samples and a mean value was used for statistical analysis.

\subsection{Dimensional Accuracy}

To assess dimensional changes during repeated irradiations, stone models were prepared by duplicating a metal model which was similar to two prepared teeth to serve as abutments for a long-span bridgework with a shoulder finish line measuring $1 \mathrm{~mm}$ in width, and a groove $1 \mathrm{~mm}$ above the finish line on the abutments serving as a cervical undercut, fixed on a metallic base (Figure 3$)(12,13)$.

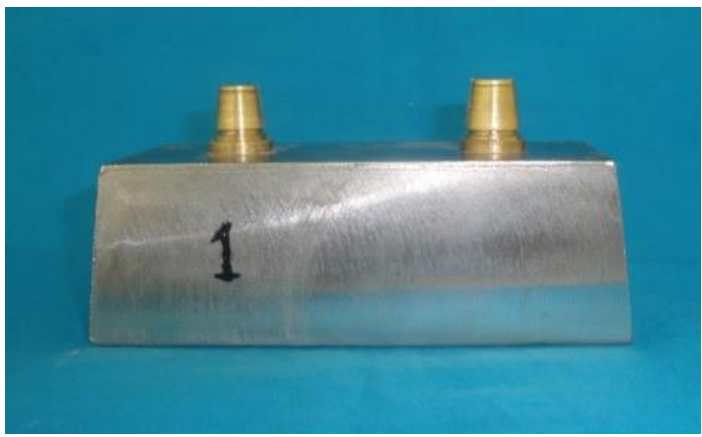

Figure 3: The model used to evaluate dimensional accuracy

To duplicate the model to stone, a 2-mm space was created using utility wax on metallic 
molds for the impression material and a total of 12 acrylic special trays (Acropars, Tehran, Iran) were prepared. The trays were stored for 24 hours before use. After application of the special tray glue into the trays, additional silicone impression material (Panasil, Kettenbach, Germany) was used to take impressions from the model, using double-mix technique. The impressions were poured with two stone products used in the former experiment. The techniques of pouring, storage, grouping and irradiation were the same as those applied for the evaluation of surface hardness (Figure 4).

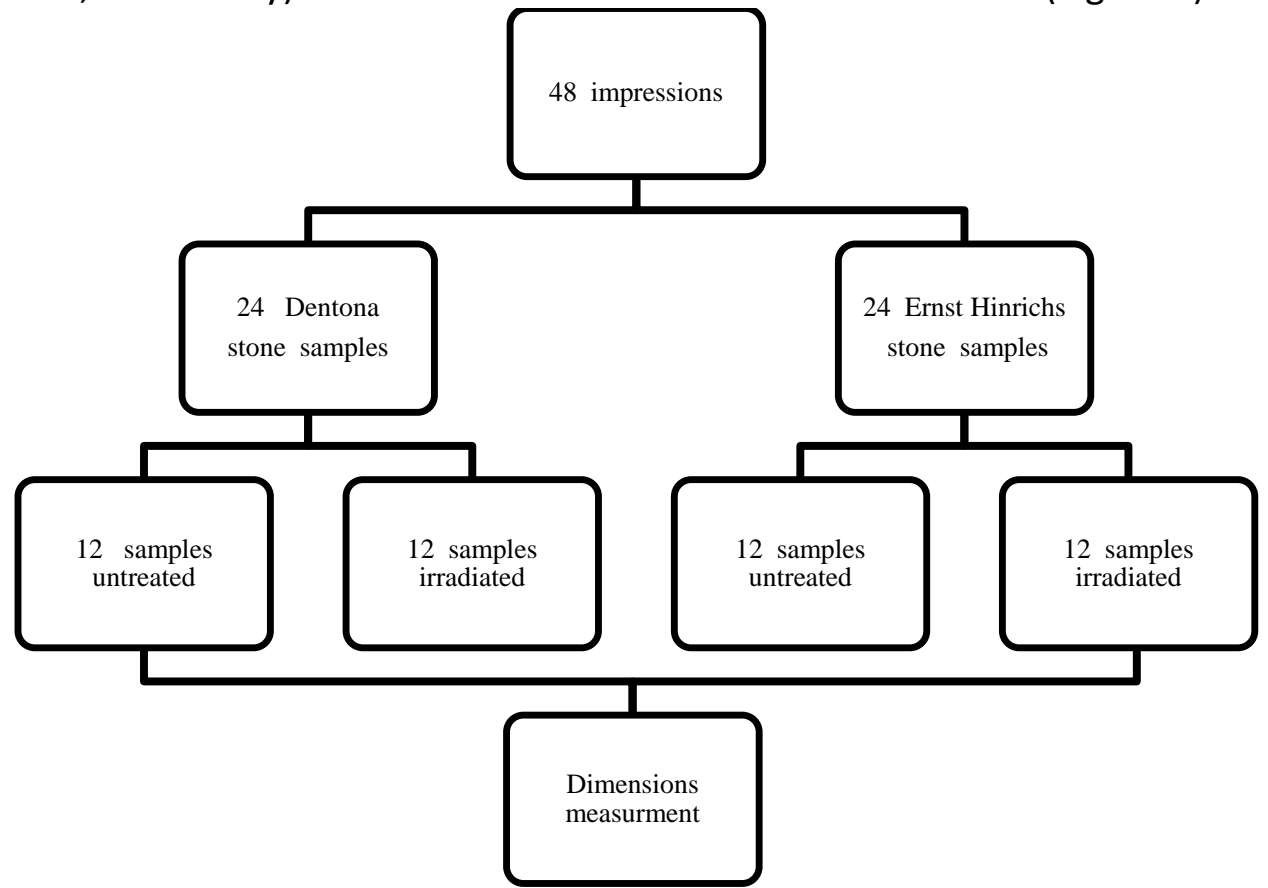

Figure 4: The flowchart of dimensional accuracy experiment

The diameter of the occlusal area and the height of the smaller die and distance between the two dies at most distant points from each other on their occlusal surfaces were measured using a calibrated digital caliper (Guanglu Digital Caliper. China) accurate to $0.01 \mathrm{~mm}$ by a blinded expert. Each dimension was measured three times and the mean of measurements was used for statistical analysis.

\section{Results}

The mean surface hardness values of case and control samples in Ernst Hinrichs stone type were 52.17, and 39.81, respectively. For the Dentona stone, mean surface hardness values of case and control samples were 44.53 and 42.89, respectively. According to t-test results, Dentona stone samples did not show a significant difference in surface hardness after irradiations ( $P=0.212$ ), while a statistically significant increase in surface hardness was observed for Ernst Hinrichs samples following irradiations $(P=0.000)$ (Table 1$)$. 
T-test

\begin{tabular}{ccccccc}
\cline { 3 - 4 } & Product & Group & Number & Mean & $\begin{array}{c}\text { Degree of } \\
\text { freedom }\end{array}$ & $P$ \\
\hline
\end{tabular}

\begin{tabular}{cccccccc} 
Dentona & Case & 36 & 44.5278 & 6.01183 & \multirow{2}{*}{1.10} & 70 & 0.212 \\
\cline { 2 - 5 } & Control & 36 & 42.8889 & 6.54120 & & \\
\hline Ernst & Case & 36 & 52.1667 & $9.56930^{*}$ & \multirow{2}{*}{6.56} & \multirow{2}{*}{70} & 0.000 \\
\cline { 2 - 5 } Hinrichs & Control & 36 & 39.8056 & $6.00866^{*}$ & &
\end{tabular}

Table 1: Comparison of surface hardness of two types of dental stones with and without irradiation

*: significantly different

With regards to dimensional accuracy, there evaluation of case samples at $\times 3$ did not reveal were no significant differences between case any holes, cracks or color changes on the and control samples (Tables 2, 3). In addition, surface of stone casts.

T-test

\begin{tabular}{cccccccc} 
Dimension & Group & Number & Mean & SD & T & $\begin{array}{c}\text { Degree of } \\
\text { freedom }\end{array}$ & P \\
\hline \multirow{2}{*}{ Diameter } & Case & 12 & 9.2444 & .04866 & & & \\
& Control & 12 & 9.2597 & .04651 & & & .1 .362 \\
\hline \multirow{2}{*}{ Height } & Case & 12 & 12.7408 & .05983 & 70 & 70 & .664 \\
& Control & 12 & 12.7347 & .05892 & & & \\
\hline \multirow{2}{*}{ Distance } & Case & 12 & 50.2544 & .06336 & -1.72 & 70 & .092
\end{tabular}

Table 2: Comparison of dimensional accuracy of the Dentona dental stone, with and without irradiation 
T-test

\begin{tabular}{|c|c|c|c|c|c|c|c|}
\hline \multirow[b]{2}{*}{ Dimension } & \multirow[b]{2}{*}{ Group } & \multirow[b]{2}{*}{ Number } & \multirow[b]{2}{*}{ Mean } & \multirow[b]{2}{*}{ SD } & \multirow{2}{*}{\multicolumn{2}{|c|}{$\begin{array}{l}\text { Degree of } \\
\text { freedom }\end{array}$}} & \multirow[b]{2}{*}{$P$} \\
\hline & & & & & & & \\
\hline \multirow{3}{*}{ Diameter } & Case & 12 & 9.2222 & .07968 & \multirow{3}{*}{-.363} & \multirow{3}{*}{70} & \multirow{3}{*}{.718} \\
\hline & & & & & & & \\
\hline & Control & 12 & 9.2303 & .10665 & & & \\
\hline \multirow{3}{*}{ Height } & Case & 12 & 12.7753 & 10953 & \multirow{3}{*}{1.410} & \multirow{3}{*}{70} & \multirow{3}{*}{.163} \\
\hline & & & & & & & \\
\hline & Control & 12 & 12.7417 & .09198 & & & \\
\hline \multirow{3}{*}{ Distance } & Case & 12 & 50.3833 & .06137 & \multirow{3}{*}{-.172} & \multirow{3}{*}{70} & \multirow{3}{*}{.864} \\
\hline & Control & & & & & & \\
\hline & comtrol & 12 & 50.3869 & 10980 & & & \\
\hline
\end{tabular}

Table 3: Comparison of dimensional accuracy of the Ernst Hinrichs dental stone, with and without irradiation

\section{Discussion}

This study was carried out to evaluate the effect of repeated microwave irradiation at 900-W energy level for 5 minutes on dimensional accuracy and surface hardness of two commercially-available dental stone materials. The results showed that, following repeated microwave irradiations, the dimensions of the cast remain unchanged and the surface hardness is either unaltered or even increased for the two stone types evaluated.

The surface hardness is an important property of the stone cast that can have direct effect on the surface resistance versus the abrasion and scratches that can damage it. The surface hardness of different stone types is inversely related to W/P ratio; the lower the water contributed in the mix, the more the surface hardness. The surface hardness is also influenced by the time that gypsum is allowed to harden after primary setting without any disturbances as heating or early drying. After final setting, the surface hardness of the stone cast remains stable until the evaporation of the extra water that can make it harder (14).

In this study, the surface hardness values were obtained for two drying techniques and two type IV stone products. The values for the casts dried in a microwave oven 24 hours after mixing, compared with those of similarly prepared casts that were air dried for 24 hours showed no significant difference for Dentona and a higher hardness for Ernst Hinrichs.

In similar study to evaluate the effect of microwave on surface hardness of stone cast, Luebke et al. (15) exposed the casts to $1450 \mathrm{~W}$ for 5 minutes to rapidly dry stone casts, 50 minutes after pouring. The results showed that the samples dried in the air had higher surface hardness after 24 and 48 hours than samples 
dried by microwaves. However, in the first 4 hours, 6 out of 8 stone products had higher surface hardness compared to control samples, that can be related to earlier water escape and drying of the surface of the samples.

Similar to surface hardness, setting expansion of stone cast is an important requisite of die materials that has a critical role in making precision restoration, because of compensation the shrinkage of impression materials. Similar to hardening, the expansion of stone mass is improved by progressive conversion of hemihydrate molecules to dihydrate crystals during the setting procedure, and therefore, the presence of water and sufficient time are necessary to deposition and cross-joining of the crystals. Elimination of water at early hours after pouring prevents expansion of the cast to the optimal value (14, 16).

In the current study, the dimensions of the cast were measured for air drying and additional microwave drying at 24 hours after mixing, and the results showed no significant difference. Consistent with this observation in dimensional accuracy, Abass et al. (8) reported duration of 10 minutes and an energy level of $850 \mathrm{~W}$ in 24 hours air-dried samples had a minimum negative effect on the dimensional stability of dental stone. Silva (10) also showed 2 hours air-dried casts can be irradiated with $800 \mathrm{~W}$ for 5 minutes without significant change in dimension when compared to 24 hours and 7 days air-dried casts. In contrast, Yap et al. (12) reported a significant decrease in cast dimensions after irradiation with 700W energy level for 40 seconds on stone samples when dried a short time after pouring.

To reproduce the real clinical and laboratory conditions where repeated disinfections of the cast is required, the current study evaluated the changes of the casts under this condition, as was done for the chemical disinfection of the stone cast $(1,2)$ and microwave disinfection of the stone casts(17).

The chemical disinfection of the stone cast should not be applied anymore because of several reasons. Primarily, stone casts have a sensitive structure to water-based solutions and chemical disinfectants and thus would be damaged if disinfected repeatedly. Moreover, the disinfection procedures are costly and timeconsuming, as for the necessity of daily preparation of a fresh solution and the time needed for drying of the cast. Additionally, these materials have a bad odor and are potentially toxic for the human and the environment. Also, there are new generations of resistant microorganisms that may not be eliminated by these compounds. Therefore, to interrupt the cast-derived cross-contamination cycle between the clinic and laboratory by a practical and efficient technique, the microwave disinfection was presented and shown to have high level microbicidal efficiency.

It is recommended that further studies are carried out with more approved microbicidal levels of microwave energy, to evaluate the effect of irradiation on the physical and mechanical properties of stone casts.

\section{Conclusion}

Considering the condition of this study, it was shown that 7 times consecutive irradiation of stone cast each 5 minutes at 900W energy level, does not have any negative effects on surface hardness and dimensional accuracy of stone cast. 


\section{References}

1. Abdullah MA. Surface detail, compressive strength, and dimensional accuracy of gypsum casts after repeated immersion in hypochlorite solution. J Prosthet Dent.2006;95:462-8.

2. Stern MA,Johnson $\mathrm{GH}$,Toolson LB.An evaluation of dental stones after repeated exposure to spray disinfectants.Part I:Abrasion and compressive strength.The journal of prosthetic dentistry.1991;65:713-8.

3. Egusa H, Watamoto T, Abe K, Kobayashi M, Kaneda Y, Ashida S, et al. An analysis of the persistent presence of opportunistic pathogens on patient-derived dental impressions and gypsum casts. The International journal of prosthodontics.2008;21:62.

4. Kumar RN, Reddy SM, Karthigeyan S, Punithavathy R, Karthik KS, Manikandan R. The effect of repeated immersion of gypsum cast in sodium hypochlorite and glutaraldehyde on its physical properties: An in vitro study. J Pharm Bioallsci.2012;4:353-7.

5. Abdelaziz KM, Combe EC, Hodges JS. The effect of disinfectants on the properties of dental gypsum, part 2: Surface properties. Journal of Prosthodontics.2002;11:234-40.

6. Berg E, Nielson O, Skuag N.High-level microwave disinfection of dental casts. Int J Prosthodont.2005;18:520-5.

7. Kalahasti D, Hegde V, Kosaraju K, Baliga S, Reddy N. K, Sujatha BK. Evaluation of Efficacy of Microwave Irradiation in Disinfecting Dental Gypsum Casts: An Ex Vivo Study. J Indian Prosthodont Soc.2013;1-12.

8. Abass SM, Mahmood MA, Khalaf BS.Effect of microwave irradiation on disinfection, dimensional accuracy, and surface porosity of dental casts. MDJ.2011;8:177-87.

9. Hasan RH. The Effect of Microwave Disinfection on Tensile Strength of Dental Gypsum.Al-Rafidain Dent J.2008;8:213-7.

10. Silva MA,Vitti RP,Consani S.Linear dimensional change, compressive strength and detail reproduction in type IV dental stone dried at room temperature and in a microwave oven. J Appl Oral Sci.2012;588-93.

11. American National Standards. American Dental Association Specification No. 25 for Dental Gypsum Products. New York. American National Standards Institute.2000;244-53.

12. Yap Au, Yap SH, Teo JC,Tay CM,Ng KL, Thean HP.Microwave drying of high-strength stones: Effects on dimensional accuracy.Oper Dent.2003;28:193-9.

13. Pardeep K.B.Comparison of dimensional accuracy using two elastomeric impression materials in fixed prosthodontics.Pakistan Oral \& Dental Journal.2010;30:537-44.

14. Sakagushi RL,Powers JM.Craig's Restorative Dental Materials, 13th ed. London; 2012. P.300-9.

15. Leubke RJ, Chan KC. Effect of microwave oven drying on surface hardness of dental gypsum products. J Prosthet Dent.1985;54:431-5.

16. Anusavice KJ ,Shen CH, Rawls HR.Phillip's Science of Dental Materials,10th ed. Philadelphia;2013.p.182-93.

17. Robati Anaraki M, Moslehifard E, Aminifar S,Ghanati H. Effect of Microwave Disinfection on Compressive and Tensile Strengths of Dental Stones.JODDD.2013;7:42-6. 